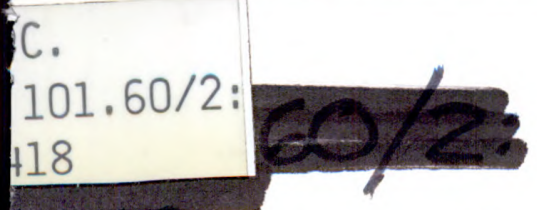

Research Report 1418

\title{
Recommendations for Improved \\ Performance Appraisal in the Federal Sector
}

\author{
Alma G. Steinberg and William P. Burke
}
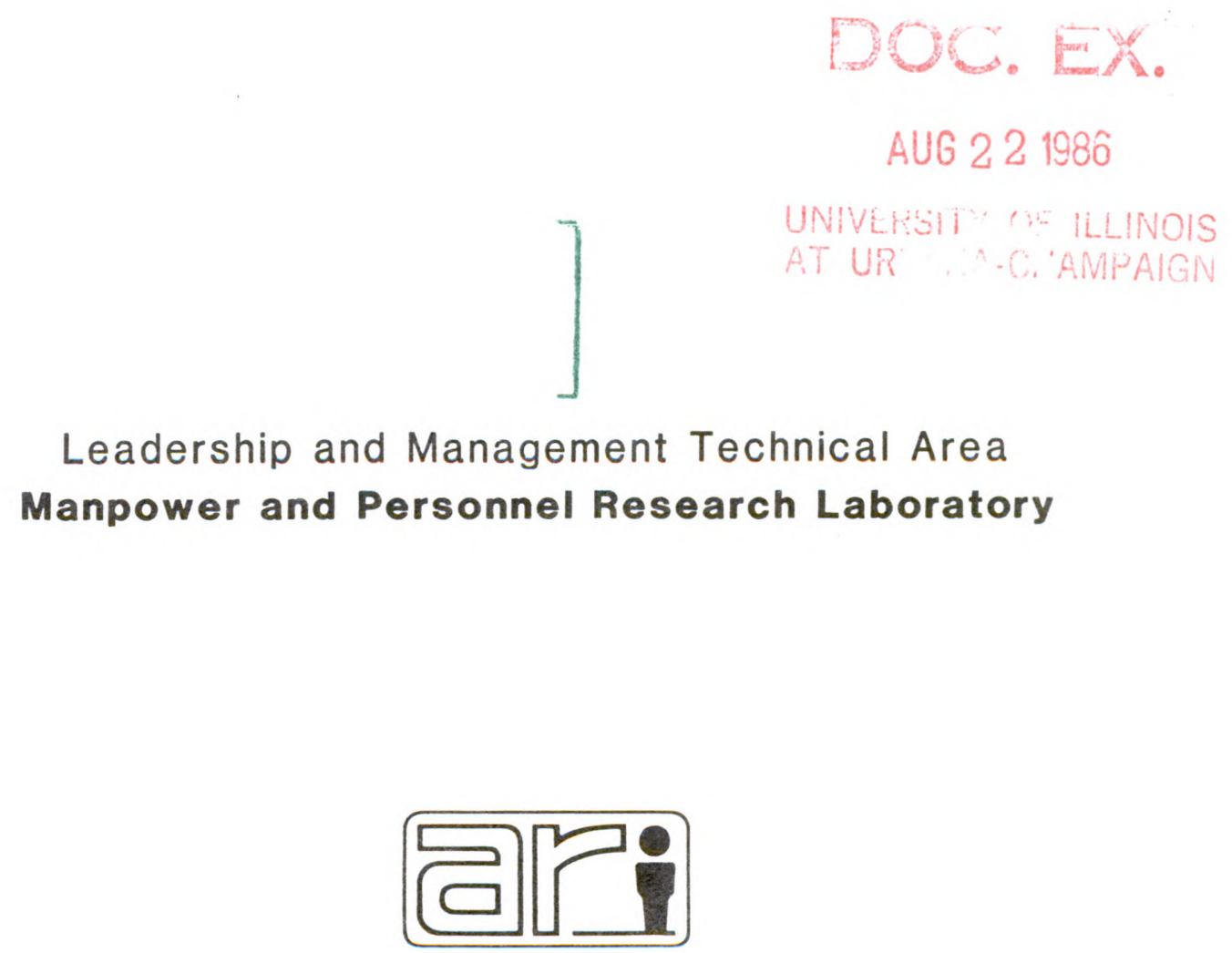

U. S. Army

Research Institute for the Behavioral and Social Sciences January 1986

Approved for public release; distribution unlimited. 